\title{
UTILIZAÇÃO DO TESTE DE RAIOS X NA AVALIAÇÃO DA QUALIDADE DE SEMENTES DE ESPÉCIES FLORESTAIS DE LAURACEAE ${ }^{1}$
}

\author{
LETICIA RENATA DE CARVALHO ${ }^{2}$, MARIA LAENE MOREIRA DE CARVALHO ${ }^{3}$ ANTONIO CLÁUDIO DAVIDE ${ }^{4}$
}

\begin{abstract}
RESUMO - O teste de raios X é uma técnica importante para a avaliação da qualidade de sementes, principalmente por ser um método não destrutivo. O objetivo deste trabalho foi verificar a ocorrência de alterações morfológicas internas por meio de raios $\mathrm{X}$ e os efeitos dessas alterações na qualidade de sementes de seis espécies de Lauraceae encontradas no sul de Minas Gerais. As sementes foram expostas a diferentes tempos e intensidades de radiação com a utilização do aparelho de raios X. A potência de $25 \mathrm{kV}$ durante dois minutos possibilita a visualização nítida de alterações morfológicas internas em sementes de Ocotea pulchella e Persea pyrifolia. Já para sementes de Nectandra grandiflora, Nectandra lanceolata e Nectandra nitidula, a intensidade de $30 \mathrm{kV}$ durante dois minutos proporciona resultados superiores. Danos internos, independentemente da causa, afetam a viabilidade das sementes, com exceção daqueles danos de menores dimensões, distantes do eixo embrionário.
\end{abstract}

Termos para indexação: análise de imagens, Ocotea pulchella, Nectandra grandiflora, Persea pyrifolia, Nectandra lanceolata, Nectandra nitidula.

\section{THE USE OF THE X-RAY TEST TO EVALUATE SEED QUALITY OF LAURACEAE FOREST SPECIES}

\begin{abstract}
The X-ray test is an important technique to evaluate seed quality, mainly because it is a non-destructive method. The objectives of this study were to adapt the X-ray method to verify the occurrence of alteration in the internal morphology and its effects on the seed quality of the species of Lauraceae which grow in the south of Minas Gerais State, Brazil. The seeds were submitted to different times and intensities of radiation exposure, using X-ray equipment. The intensity of $25 \mathrm{kV}$ for two minutes allowed clear visualization of alteration in internal morphology of the seeds of Ocotea pulchella and Persea pyrifolia. In seeds of Nectandra grandiflora, Nectandra lanceolata and Nectandra nitidula, the intensity of $30 \mathrm{kV}$ for two minutes gave better results. Internal damage, irrespective of its origin, affected seed viability, with exception of the smaller injuries located far from the embryonic axis.
\end{abstract}

Index terms: image analysis, Ocotea pulchella, Nectandra grandiflora, Persea pyrifolia, Nectandra lanceolata, Nectandra nitidula.

\footnotetext{
${ }^{1}$ Submetido em 05/11/2008. Aceito para publicação em 27/07/2009.Parte da tese de doutorado do primeiro autor, defendida na Universidade Federal de Lavras.

${ }^{2}$ Engenheira Florestal, Dra., Profa., Setor de Ciências Agrárias, Universidade José do Rosário Vellano, Rodovia MG 178, Km 0, Caixa Postal 23, CEP
}

37130-000, Alfenas, MG. drleticia2005@yahoo.com.br

${ }^{3}$ Engenheira Agrônomo, Dra., Profa., Departamento de Agronomia/UFLA, Caixa Postal 3037, CEP 37200-000, Lavras, MG. mlaenemc@dag.ufla.br

${ }^{4}$ Engenheiro Agrônomo, Dr., Prof. Titular, Departamento de Ciências Florestais/UFLA. acdavide@ufla.br 


\section{INTRODUÇÃOO}

A crescente demanda por sementes de espécies florestais nativas, por programas de produção e conservação do setor florestal brasileiro, tem gerado a necessidade de desenvolvimento de tecnologias para a avaliação da qualidade destas sementes. Dentre as técnicas que têm sido desenvolvidas, destaca-se o uso de raios $\mathrm{X}$.

$\mathrm{O}$ teste de raios $\mathrm{X}$ é considerado um método rápido e não destrutivo que tem o objetivo de detectar sementes vazias, cheias e presença de danos internos causados por insetos ou danos mecânicos (ISTA, 1999, 2004). $\mathrm{O}$ princípio da técnica consiste na absorção de raios $\mathrm{X}$ em diferentes quantidades pelos diferentes tecidos das sementes, o que depende da espessura, da densidade e da composição desses tecidos, além do comprimento de onda da radiação (Bino et al., 1993; ISTA, 1999, 2004; Simak, 1991). As sementes são colocadas entre uma fonte de baixa energia de raios X e um filme fotossensível. Quando os raios $\mathrm{X}$ atravessam a semente e atingem o filme, é criada uma imagem latente. Após o processamento do filme, uma imagem de sombras claras e escuras é formada, criando uma imagem permanente no filme radiográfico (ISTA, 1999, 2004; Simak, 1991). As áreas mais escuras da radiografia correspondem àquelas partes em que os raios $\mathrm{X}$ penetram mais facilmente, enquanto que áreas mais claras representam partes mais densas da semente (Simak, 1991).

O desenvolvimento de metodologia para a análise de sementes por meio de radiografias para espécies florestais tropicais vem sendo realizado, principalmente, com o objetivo de melhorar a qualidade fisiológica dos lotes de sementes. A melhoria da qualidade de lotes pode ser realizada pelo descarte de sementes com danos internos, como foi observado em sementes de Peltophorum dubium (Oliveira et al., 2003), embriões com danos ou anormalidades, como observado em Lithraea molleoides (Machado e Cícero, 2003), sementes vazias ou com danos internos, como em Tabebuia serratifolia e Tabebuia impetiginosa (Oliveira et al., 2004), sementes vazias ou mal formadas, como em Eremanthus incanus e Eremanthus erythropappus, (Tonetti, 2004) e sementes predadas por insetos, como em Eugenia handrana (Masetto, 2005).

A análise de sementes por meio de raios $\mathrm{X}$ tem grande importância em bancos de sementes para a conservação ex situ de germoplasma, a exemplo do Millennium Seed Bank, onde a técnica é utilizada (Terry et al., 2003). A análise das sementes pela técnica de raios $\mathrm{X}$ permite a seleção de sementes sem danos para formação de lotes de melhor qualidade contribuindo para a conservação das sementes nos bancos de germoplasma.

As espécies da família Lauraceae destacam-se pelo valor econômico e ecológico. Nectandra lanceolata é indicada para arborização de áreas abertas. Persea pyrifolia, Ocotea pulchella e Ocotea corymbosa são indicadas para o paisagismo (Lorenzi, 1992). Nectandra nitidula pode ser utilizada na arborização urbana (Lorenzi, 1998). Esta última espécie, assim como Ocotea pulchella e Persea pyrifolia, foi indicada para a recuperação de áreas no entorno de nascentes da sub-bacia do ribeirão Santa Cruz, município de Lavras, Sul de Minas Gerais (Pinto, 2003). As espécies citadas anteriormente pertencem ao grupo ecológico das climácicas (Carvalho et al., 1999; Oliveira-Filho et al., 1995; Pinto, 2003; Souza, 1997). A sazonalidade na produção de sementes pode ocorrer em espécies climácicas (Bonner, 1990), como foi observado para Ocotea catharinensis, Lauraceae (Silva, 1997). Além disso, sementes ou frutos em desenvolvimento podem sofrer severos danos durante a maturação, devido à predação por insetos, a exemplo de sementes de Phoebe porosa (Vernalha, 1953) e Aniba rosaeodora (Rosa e Ohashi, 1999). Dentre os fatores que influenciam o armazenamento das sementes encontram-se a longevidade inerente à espécie e a qualidade inicial das sementes (Carvalho e Von Pinho, 1997). Várias espécies de lauraceae tiveram suas sementes classificadas como recalcitrantes como as seguintes espécies envolvidas neste estudo: Persea pyrifolia e Nectandra nitidula (Davide et al., 1993); Nectandra lanceolata, Nectandra grandiflora, Ocotea pulchella e Ocotea corymbosa (Carvalho, 2006). Sementes recalcitrantes toleram a secagem somente até 20 a $35 \%$ de umidade (Chin, 1989), o que dificulta o armazenamento. Além disso, a qualidade inicial dessas sementes pode ser comprometida pela irregularidade de maturação dos frutos e pela predação por insetos.

$\mathrm{O}$ teste de raios $\mathrm{X}$, após o beneficiamento, pode permitir a detecção de sementes infestadas por insetos e ou a presença de danos físicos invisíveis a olho nu, que podem comprometer a qualidade das sementes e, conseqüentemente, o potencial de armazenamento. Portanto, os objetivos deste trabalho foram adequar o método de raios X para verificar a ocorrência de alterações morfológicas internas e seus efeitos na qualidade de sementes de espécies de Lauraceae. 


\section{MATERIAL E MÉTODOS}

\section{Espécies estudadas e origem das sementes}

O estudo envolveu seis espécies de Lauraceae, de ocorrência na região Sul de Minas Gerais, nos municípios de Itumirim, Perdões, Lavras e Poços de Caldas (Tabela 1).

O município de Itumirim localiza-se a uma altitude de $870 \mathrm{~m}$ e encontra-se a $21^{\circ} 19^{\prime} 02^{\prime \prime} \mathrm{S}$ e $44^{\circ} 52^{\prime} 14^{\prime \prime} \mathrm{W}$. O município de Perdões encontra-se a $840 \mathrm{~m}$ de altitude, $21^{\circ} 05^{\prime} 27^{\prime}$ 'S e $45^{\circ} 05^{\prime} 29^{\prime \prime} \mathrm{W}$ de longitude. O município de Lavras está a $919 \mathrm{~m}$ de altitude e encontra-se a $21^{\circ} 14^{\prime} \mathrm{S}$ de latitude e $45^{\circ} 00^{\prime} \mathrm{W}$ de longitude (Brasil, 1992a). O clima da região de Lavras é classificado como de transição entre Cwb e Cwa, ou seja, verões quentes e úmidos com inverno seco e moderado, de acordo com a classificação de Köppen (Köppen, 1936). A temperatura e a precipitação pluvial média anual são iguais a $19,4^{\circ} \mathrm{C}$ e $1.529,7 \mathrm{~mm}$, respectivamente (Brasil, 1992a). O município de Poços de Caldas está situado em um planalto elíptico e encontrase a $21^{\circ} 50^{\prime} 13^{\prime \prime} \mathrm{S}$ de latitude e $46^{\circ} 34^{\prime} 10^{\prime \prime} \mathrm{W}$ de longitude, a uma altitude média de $1.300 \mathrm{~m}$. O clima da região, de acordo com a classificação de Köppen, é do tipo Cwb, ou seja, mesotérmico com inverno seco e verão brando. A temperatura média anual é de $17,6{ }^{\circ} \mathrm{C}$ e a precipitação pluvial média anual é de $1.695 \mathrm{~mm}$.

TABELA 1. Espécies estudadas, local, data e número de matrizes coletadas.

\begin{tabular}{lccc}
\hline \multicolumn{1}{c}{ Espécie } & Município de coleta & Época de coleta & Número de matrizes \\
\hline Nectandra grandiflora Nees & Perdões & Janeiro/2004 & 5 \\
Nectandra lanceolata Nees & Itumirim & Dezembro/ 2003 & 2 \\
Nectandra nitidula Nees \& Mart. & Poços de Caldas & Dezembro/ 2003 & 6 \\
Ocotea pulchella Nees (Mez) & Lavras & Outubro/2003 & 4 \\
Persea pyrifolia Nees \& Mart. & Lavras & Janeiro de 2003 & 4 \\
\hline
\end{tabular}

Coleta dos frutos - As árvores das espécies Nectandra grandiflora, Nectandra lanceolata e Ocotea pulchella foram encontradas em agrupamentos. A coleta dos frutos foi realizada diretamente das matrizes distanciadas umas das outras aproximadamente $50 \mathrm{~m}$, seguindo recomendações de Sebben (2002). Árvores matrizes de Persea pyrifolia foram encontradas isoladas, distantes, aproximadamente, $100 \mathrm{~m}$ umas das outras. A colheita dos frutos foi realizada na época de dispersão, quando foi observada a queda espontânea. Durante a coleta, foi utilizado podão para cortar os ramos que continham frutos com diferentes colorações devido à irregularidade de maturação. Após a coleta, os frutos foram acondicionados em sacos de aniagem e transportados para o Laboratório de Sementes Florestais da Universidade Federal de Lavras. Os dados sobre a época de coleta e o número de matrizes coletadas para a formação do lote de sementes de cada espécie encontram-se na Tabela 1.

No trabalho foram utilizados apenas frutos maduros. Frutos de Nectandra grandiflora, Nectandra lanceolata, Nectandra nitidula, e de Ocotea pulchella permaneceram acondicionados por três dias em sacos de aniagem e os de Persea pyrifolia permaneceram por 24 horas em saco de aniagem antes do beneficiamento.

Extração e beneficiamento das sementes - Os frutos foram macerados em peneira sob água corrente, para a eliminação da polpa. Após a remoção da polpa, as sementes foram lavadas em solução de hipoclorito de sódio $1,0 \%$, durante cinco minutos. Sementes que boiaram na solução foram descartadas e o restante foi enxaguado três vezes em água. O excesso de água foi retirado com papel toalha. O trabalho envolveu apenas sementes que não apresentaram danos visuais.

Após o beneficiamento, sementes de Persea pyrifolia permaneceram durante 90 dias acondicionadas em embalagem de polietileno $(0,03 \mathrm{~mm}$ de espessura) em câmara fria $\left(5^{\circ} \mathrm{C}, 60 \% \mathrm{UR}_{\mathrm{ar}}\right)$ para a superação de dormência, conforme Davide et al. (2003). O grau de umidade dessas sementes, antes e após o resfriamento, foi de $40,0 \%$. As sementes das demais espécies foram utilizadas logo após o beneficiamento.

A partir de cada lote, foram retiradas amostras para a determinação do grau de umidade, definição de metodologia para análise radiográfica e verificação do efeito de alterações morfológicas internas na viabilidade das sementes. 
Determinação do grau de umidade - A determinação do grau de umidade foi realizada em estufa sob temperatura de $103{ }^{\circ} \mathrm{C} \pm 2{ }^{\circ} \mathrm{C}$, durante 17 horas. Os resultados foram expressos em porcentagem com base na massa úmida das sementes, conforme as Regras para Análise de Sementes (Brasil, 1992b). Para todas as espécies, foram utilizadas quatro repetições. Para Nectandra nitidula, Ocotea pulchella e Persea pyrifolia foram utilizadas seis sementes cortadas transversalmente ao meio. Para Nectandra grandiflora e Nectandra lanceolata, foram utilizadas três sementes por repetição, cortadas transversalmente ao meio seguido de corte longitudinal resultando em quatro partes.

Definição da metodologia para análise radiográfica das sementes - As sementes foram acondicionadas em bandejas de isopor com células confeccionadas de acordo com as dimensões das sementes de cada espécie. As sementes foram posicionadas de forma que a região do eixo embrionário ficasse na parte superior das células. $\mathrm{O}$ aparelho de raios $\mathrm{X}$ utilizado foi o Faxitron HP, modelo 43855AX; o filme radiográfico foi Kodak Min-R 2000, com dimensões de $18 \times 24 \mathrm{~cm}$. A revelação foi realizada em uma processadora de revelação de raios X marca Kodak, modelo M35X OMAT. Para cada espécie, foram utilizadas 100 sementes que foram expostas a diferentes combinações de intensidade e tempo de exposição à radiação. Para sementes de Nectandra nitidula e Nectandra lanceolata, foram testados $30 \mathrm{kV}$ e $40 \mathrm{kV}$ durante 2 e 3 minutos; para Nectandra grandiflora, foi testada a potência de $30 \mathrm{kV}$ durante 2 e 3 minutos; sementes de Ocotea pulchella foram expostas à radiação de 20,25 e $30 \mathrm{kV}$ durante 2 e 3 minutos e para sementes de Persea pyrifolia foi testada a intensidade de $25 \mathrm{kV}$ durante 2 e 3 minutos. As combinações de intensidade e tempo de exposição à radiação, relacionadas anteriormente, foram definidas após pré-testes realizados para cada espécie.

Separação das sementes de acordo com a análise radiográfica - Utilizando-se a combinação de tempo e intensidade de radiação que permitiu a visualização mais nítida das estruturas internas das sementes, 100 sementes de Nectandra grandiflora e 200 sementes das outras espécies foram radiografadas e separadas em duas categorias: sementes com danos e sementes sem danos. As sementes com danos foram subdivididas em quatro subcategorias:

- sementes com danos pequenos: danos que atingiram menos de $50 \%$ do embrião;

- sementes com danos severos: danos que atingiram, no mínimo, $50 \%$ do embrião;

- sementes com danos devido à predação: sementes com características de predação, como orifícios ou presença de larvas, independente do dano ser pequeno ou severo;

- sementes mal formadas: má formação do tecido cotiledonar.

Avaliação da viabilidade para as sementes radiografadas - Foi realizado teste de germinação sobre areia previamente lavada e autoclavada, umedecida sempre que necessário. $\mathrm{O}$ teste foi realizado a $25^{\circ} \mathrm{C}$, sob luz constante, conforme Davide et al. (2003). A germinação foi considerada como a formação de plântulas normais $(1 \mathrm{~cm}$ de epicótilo com primórdios foliares e raiz primária) sendo anotadas sementes dormentes, sementes mortas e plântulas anormais (ausência de pelo menos uma das estruturas descritas anteriormente para plântulas normais) no final do teste. A duração do teste foi de 69 dias para Nectandra nitidula, Nectandra grandiflora e Persea pyrifolia, 80 dias para Nectandra lanceolata e 50 dias para Ocotea pulchella. Como não foram encontradas informações na literatura, os períodos dos testes de germinação descritos anteriormente foram definidos com a estabilização da germinação (14 dias sem a ocorrência de germinação) após o início da mesma.

A interpretação dos dados foi efetuada verificandose possíveis correspondências entre a análise radiográfica das sementes com as respectivas plântulas ou sementes resultantes no final do teste de germinação, conforme Machado e Cícero (2003).

\section{RESULTADOS E DISCUSSÃO}

O grau de umidade das sementes das espécies estudadas variou de $39,8 \%$ a $50,6 \%$, verificado para sementes de Persea pyrifolia e Ocotea pulchella respectivamente (Tabela 2). De acordo com Simak (1991), a umidade das sementes influencia a densidade ótica, ou seja, quanto menor a umidade das sementes, maior a densidade ótica, o que possibilita maior diferenciação das estruturas internas das sementes visualizadas nas radiografias. Dessa forma, a alta umidade das sementes pode ter influenciado a nitidez de visualização, como a distinção entre eixo embrionário e cotilédones (Figuras 1B, 2B, 3B, 4B e 5B). Apesar disso, foi possível observar alterações morfológicas internas por meio das radiografias (Figuras 1C, 2C, 3C, 4C e 5C). 
TABELA 2. Grau de umidade e resultado geral do teste de germinação com base no total de sementes utilizado para cada espécie. PN: plântulas normais; PA: plântulas anormais; SD: sementes dormentes; SM: sementes mortas.

\begin{tabular}{lcllrr}
\hline Espécies & Grau de umidade $(\%)$ & PN $(\%)$ & PA $(\%)$ & SD \%) & SM $(\%)$ \\
\hline Nectandra grandiflora & 42,4 & 81,0 & 0,0 & 6,0 & 13,0 \\
Nectandra lanceolata & 42,6 & 82,5 & 4,0 & 8,5 & 5,0 \\
Nectandra nitidula & 39,7 & 54,5 & 7,5 & 4,0 & 34,0 \\
Ocotea pulchella & 50,6 & 81,0 & 4,0 & 11,0 & 4,0 \\
Persea pyrifolia & 39,8 & 92,5 & 0,0 & 4,0 & 3,5 \\
\hline
\end{tabular}

$\mathrm{A}$

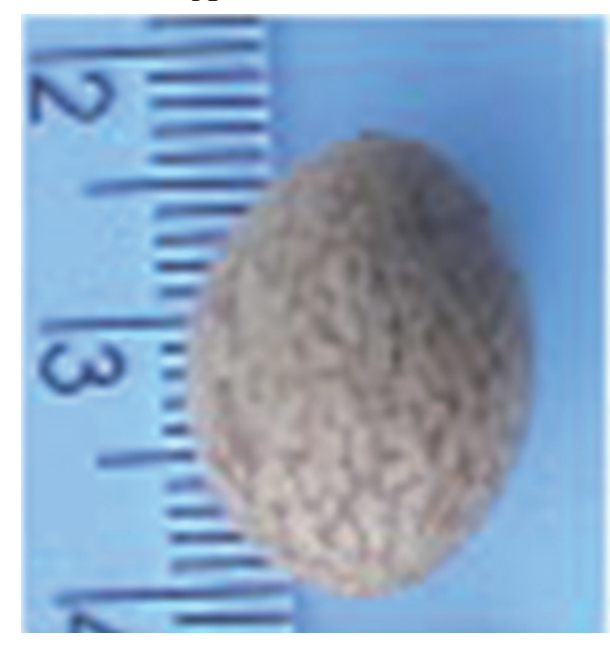

B

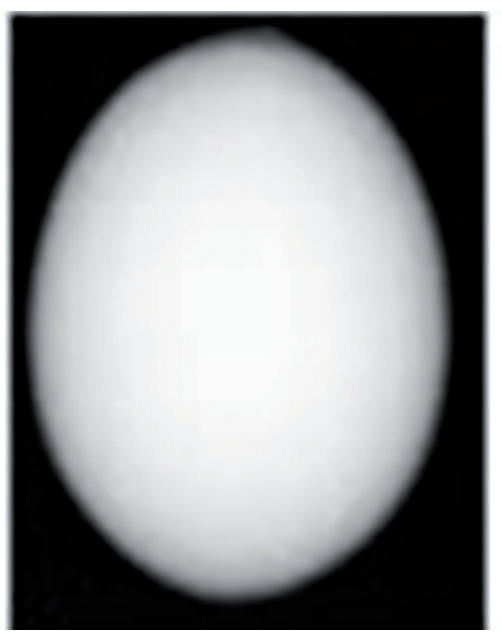

$\mathrm{C}$

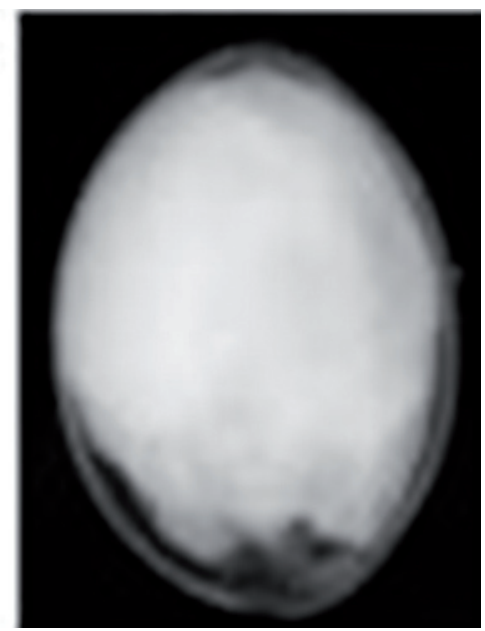

FIGURA 1. Sementes de Nectandra lanceolata(A); radiografia de semente sem dano (B) e radiografia de semente mal formada $(C)$

A

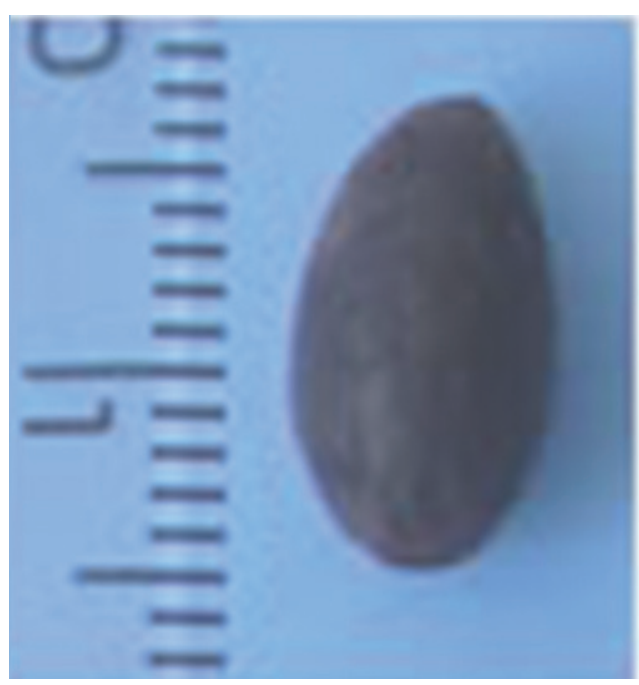

$\mathrm{B}$

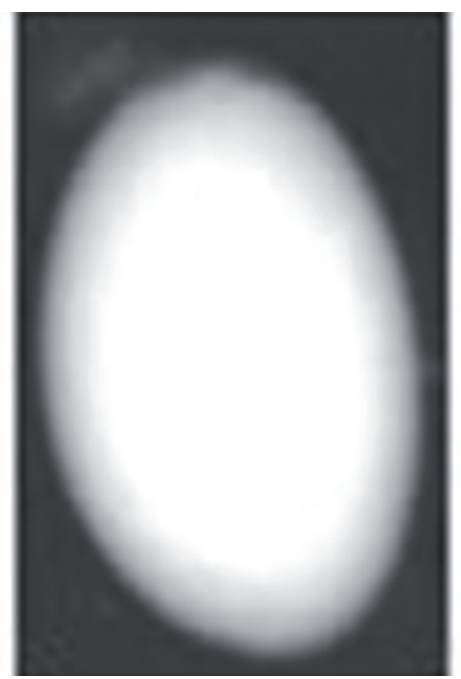

$\mathrm{C}$

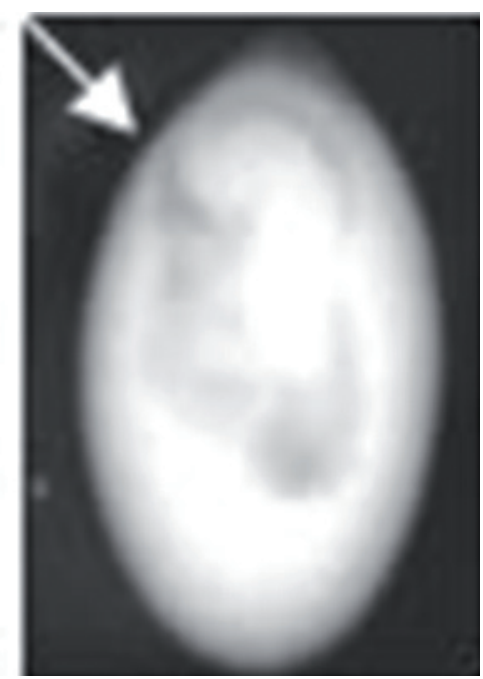

FIGURA 2. Sementes de Nectandra nitidula (A); radiografia de semente sem dano (B) e radiografia de semente predada com presença de larva $(C)$ 
A

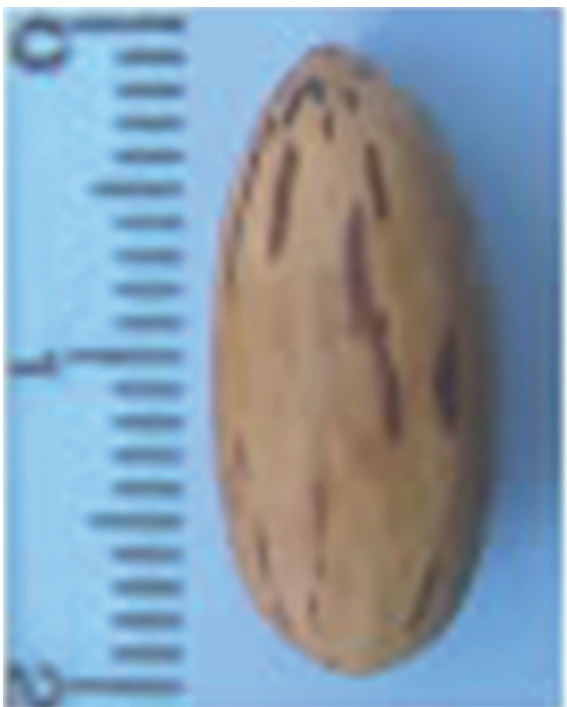

$\mathrm{B}$

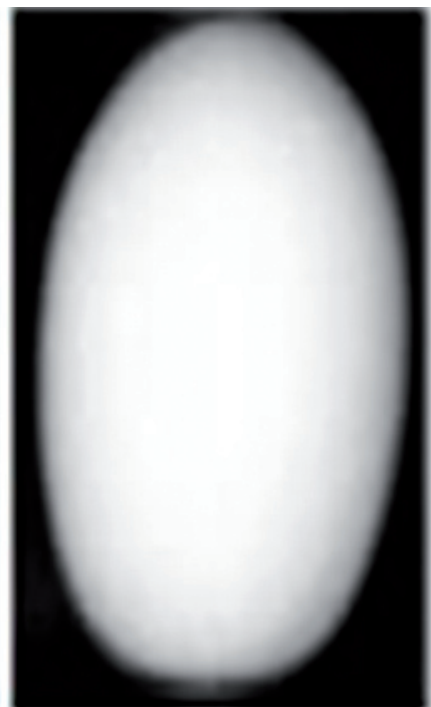

$\mathrm{C}$

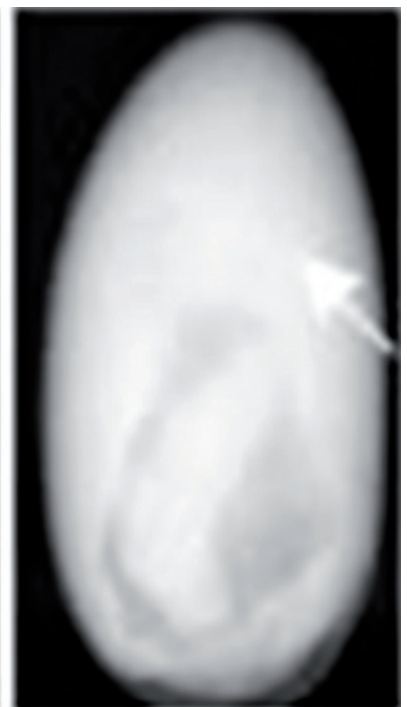

FIGURA 3. Sementes de Nectandra grandeiflora (A); radiografia de semente sem dano (B) e radiografia de semente predada com presença de larva(C)

A

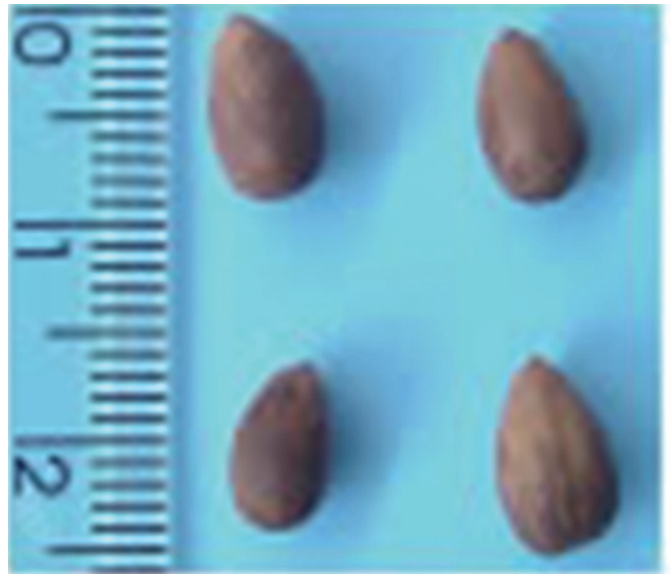

$\mathrm{B}$

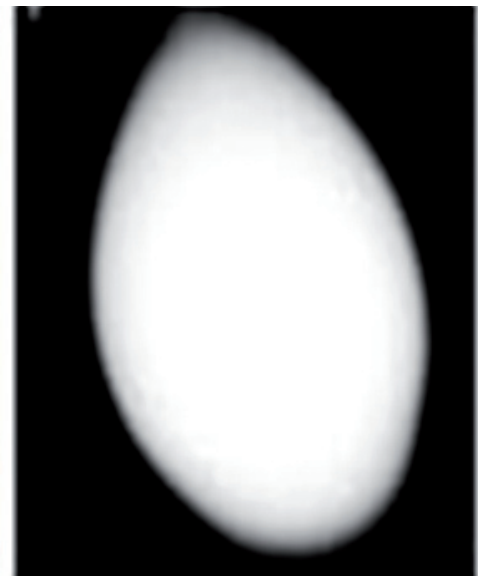

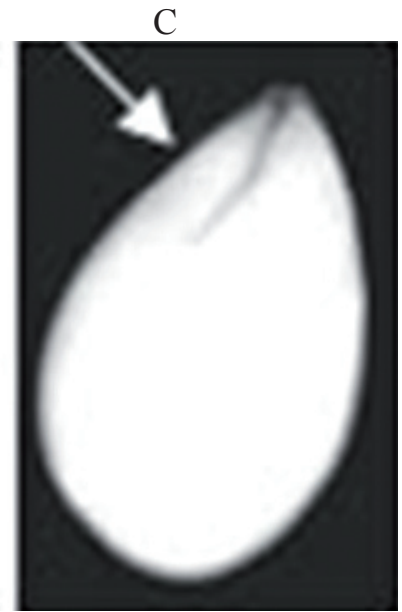

FIGURA 4. Sementes de Ocotea pulchella (A); radiografia de semente sem dano (B) e radiografia de semente com pequeno dano na região do eixo embrionário $(\mathrm{C})$

A

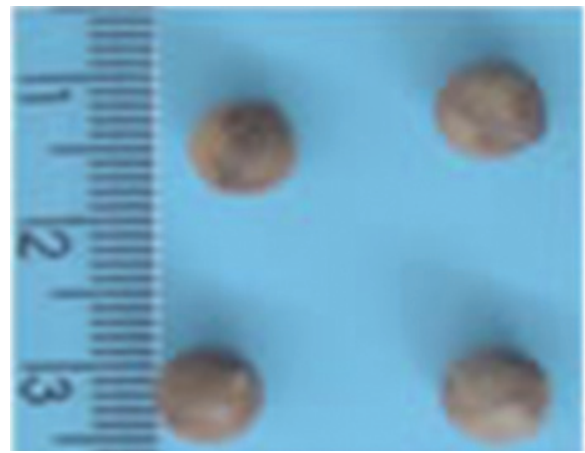

B

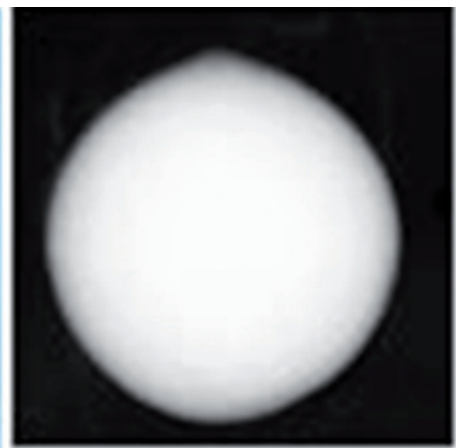

$\mathrm{C}$

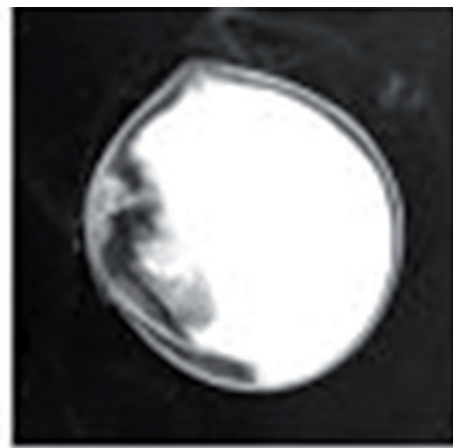

FIGURA 5. Sementes de Persea pyrifolia (A); radiografia de semente sem dano (B) e radiografia de semente predada (C) 
Dentre as combinações de potência e tempo testados, para sementes de Nectandra grandiflora, Nectandra. lanceolata e Nectandra nitidula foi selecionada a combinação de $30 \mathrm{kV}$, durante dois minutos, que proporcionou melhor visualização dos danos internos. Para sementes de Ocotea pulchella e de Persea pyrifolia, foi selecionada a combinação de $25 \mathrm{kV}$, durante dois minutos. $\mathrm{O}$ fato da mesma combinação de tempo e potência ter sido eficiente para a verificação de danos internos em sementes de espécies diferentes pode ter ocorrido devido à semelhança morfológica entre as sementes de Nectandra (figuras 1A, 2A e 3A) e entre aquelas de Ocotea pulchella e Persea pyrifolia (Figuras 4A e 5A). Da mesma forma, Oliveira et al. (2004) verificaram que a potência de $55 \mathrm{kV}$, durante 25 segundos, possibilitou a visualização da morfologia interna de sementes de Tabebuia serratifolia e Tabebuia impetiginosa. Para a análise radiográfica de sementes de espécies florestais têm sido utilizados tempos que variam de 10 segundos a 4 minutos, com intensidade de 10 a 55kV (Battisti et al., 2000; Mattos e Medeiros, 2000;
Oliveira et al., 2003; Oliveira et al., 2004).

As sementes das espécies estudadas apresentaram maior porcentagem de sementes da categoria sem dano, que resultaram em maior porcentagem de plântulas normais e menor porcentagem de sementes mortas em relação àquelas com danos (Tabela 3). Para todas as espécies, foi observada, na categoria de sementes sem dano, a ocorrência de sementes intumescidas que não apresentaram protrusão de raiz primária, o que pode ter ocorrido devido à dormência. Espécies de Lauraceae podem apresentar sementes com dormência fisiológica (Baskin e Baskin, 1998) e sementes com dormência causada por resistência mecânica (Bilia et al, 1998). Para a germinação de diásporos de Ocotea corymbosa foi constatado impedimento mecânico causado pelo endocarpo coriáceo (Bilia et al, 1998). Por outro lado, de acordo com Burg et al.(1994), devido à variação natural, algumas sementes, que não apresentaram danos pelo teste de raios $\mathrm{X}$, podem não germinar devido a infecções invisíveis por microrganismos ou danos fisiológicos.

TABELA 3. Porcentagem de sementes em cada categoria, obtida por meio da análise radiográfica da morfologia interna das sementes e resultados do teste de germinação para cada categoria. PN: plântulas normais; PA: plântulas anormais; SD: sementes dormentes; SM: sementes mortas.

\begin{tabular}{llcrrrr}
\hline Espécies & Categorias & Porcentagem de sementes & PN $(\%)$ & PA $(\%)$ & SD $(\%)$ & SM $(\%)$ \\
\hline Nectandra & Sem dano & 82,0 & 92,7 & 0,0 & 7,3 & 0,0 \\
grandiflora & Com dano & 18,0 & 27,8 & 0,0 & 0,0 & 72,2 \\
Nectandra & Sem dano & 96,5 & 84,5 & 4,1 & 8,8 & 2,6 \\
lanceolata & Com dano & 3,5 & 28,6 & 0,0 & 0,0 & 71,4 \\
Nectandra & Sem dano & 54,0 & 85,2 & 5,6 & 7,4 & 1,8 \\
nitidula & Com dano & 46,0 & 18,5 & 9,8 & 0,0 & 71,7 \\
Ocotea & Sem dano & 97,5 & 82,6 & 3,1 & 11,3 & 3,0 \\
pulchella & Com dano & 2,5 & 20,0 & 40,0 & 0,0 & 40,0 \\
Persea & Sem dano & 97,0 & 95,4 & 0,0 & 4,1 & 0,5 \\
pyrifolia & Com dano & 3,0 & 0,0 & 0,0 & 0,0 & 100,0 \\
\hline
\end{tabular}

Para sementes de Nectandra grandiflora, Nectandra lanceolata e Nectandra nitidula, a maior porcentagem de danos ocorreu devido à predação por insetos (Tabela 4). Os lotes de sementes de Nectandra nitidula e Nectandra grandiflora apresentaram 5,0\% e 10,0\%, respectivamente, de infestação por insetos na fase de larva, o que pôde ser observado pelas radiografias (Figuras $2 \mathrm{C}$ e $3 \mathrm{C}$ ). $\mathrm{O}$ inseto predador de sementes de Nectandra nitidula é um coleóptero pertencente ao gênero Heilipus. A sua identificação foi realizada no Departamento de Zoologia da Universidade Federal do Paraná.

Sementes de espécies silvestres estão sujeitas aos seus predadores naturais, o que pode lhes causar severos danos. Vernalha (1953) observou que sementes de Phoebe porosa, Lauraceae, sofre severos danos causados pelo inseto Heilipus parvulus Bohn. Rosa e Ohashi (1999) também observaram predação de frutos por insetos que podem causar danos em sementes de Aniba rosaeodora. A possibilidade de detecção de sementes infestadas é importante, pois possibilita o descarte das mesmas, 
melhorando a qualidade do lote, o que contribui para a conservação das sementes durante o armazenamento. Além disso, evita a transferência de insetos para outras regiões.

Dentre os danos encontrados para sementes de Ocotea pulchella foi observada maior porcentagem de danos pequenos (Tabela 4). Para as sementes dessas espécies ocorreram danos mecânicos, provavelmente causados pelo beneficiamento, ou seja, durante a maceração dos frutos em peneira sob água corrente (Figura 4C).

TABELA 4. Resultados da avaliação radiográfica da morfologia interna de sementes de Lauraceae com danos e resultados do teste de germinação para cada subcategoria. PN: plântulas normais; PA: plântulas anormais; SD: sementes dormentes; SM: sementes mortas.

\begin{tabular}{|c|c|c|c|c|c|c|}
\hline Espécies & $\begin{array}{l}\text { Subcategorias de } \\
\text { danificadas }\end{array}$ & $\begin{array}{l}\text { Porcentagem de } \\
\text { sementes } \\
\text { com danos }\end{array}$ & $\begin{array}{l}\mathrm{PN} \\
(\%)\end{array}$ & $\begin{array}{l}\mathrm{PA} \\
(\%)\end{array}$ & $\begin{array}{l}\mathrm{SD} \\
(\%)\end{array}$ & $\begin{array}{l}\mathrm{SM} \\
(\%)\end{array}$ \\
\hline \multirow{4}{*}{$\begin{array}{l}\text { Nectandra } \\
\text { grandiflora }\end{array}$} & Pequenos danos & 27,8 & 100 & 0 & 0 & 0 \\
\hline & Danos severos & 0,0 & 0 & 0 & 0 & 0 \\
\hline & Predadas & 55,6 & 0 & 0 & 0 & 100 \\
\hline & Mal formadas & 16,6 & 0 & 0 & 0 & 100 \\
\hline \multirow{4}{*}{$\begin{array}{l}\text { Nectandra } \\
\text { lanceolata }\end{array}$} & Pequenos danos & 0,0 & 0 & 0 & 0 & 0 \\
\hline & Danos severos & 14,3 & 0 & 0 & 0 & 100 \\
\hline & Predadas & 57,1 & 50 & 0 & 0 & 50 \\
\hline & Mal formadas & 28,6 & 0 & 0 & 0 & 100 \\
\hline \multirow{4}{*}{$\begin{array}{l}\text { Nectandra } \\
\text { nitidula }\end{array}$} & Pequenos danos & 0,0 & 0 & 0 & 0 & 0 \\
\hline & Danos severos & 2,2 & 0 & 0 & 0 & 100 \\
\hline & Predadas & 80,4 & 23 & 12 & 0 & 65 \\
\hline & Mal formadas & 17,4 & 0 & 0 & 0 & 100 \\
\hline \multirow{4}{*}{$\begin{array}{l}\text { Ocotea } \\
\text { pulchella }\end{array}$} & Pequenos danos & 80,0 & 25 & 25 & 0 & 50 \\
\hline & Danos severos & 0,0 & 0 & 0 & 0 & 0 \\
\hline & Predadas & 20,0 & 0 & 0 & 0 & 100 \\
\hline & Mal formadas & 0,0 & 0 & 0 & 0 & 0 \\
\hline \multirow{4}{*}{$\begin{array}{l}\text { Persea } \\
\text { pyrifolia }\end{array}$} & Pequenos danos & 33,3 & 0 & 0 & 0 & 100 \\
\hline & Danos severos & 16,7 & 0 & 0 & 0 & 100 \\
\hline & Predadas & 33,3 & 0 & 0 & 0 & 100 \\
\hline & Mal formadas & 16,7 & 0 & 0 & 0 & 100 \\
\hline
\end{tabular}

Danos pequenos, independente da causa, causaram a morte das sementes quando ocorreram na região do eixo embrionário. A ocorrência destes danos distantes do eixoembrionário não afetou a germinação das sementes, a exemplo de sementes de Nectandra grandiflora (Tabela 4). Danos devidos à predação causaram a morte das sementes sempre que atingiram região próxima ao eixo embrionário e ou, no mínimo, 50,0\% do embrião. Já sementes com danos severos ou mal formadas sempre resultaram em sementes mortas (Tabela 4).

De acordo com os resultados deste trabalho, o teste de raios $\mathrm{X}$ pode ser considerado como uma técnica adequada para a avaliação da qualidade de sementes das espécies de Lauraceae estudadas, possibilitando a melhoria da qualidade 
do lote pelo descarte de sementes com danos.

\section{CONCLUSÕES}

A potência de $25 \mathrm{kV}$, durante 2 minutos, possibilita a visualização nítida de alterações da morfologia interna de sementes de Ocotea pulchella e de Persea pyrifolia. Já para sementes de Nectandra grandiflora, de Nectandra lanceolata e de Nectandra nitidula, a combinação de $30 \mathrm{kV}$, durante 2 minutos, possibilita a melhor visualização de alterações da morfologia interna.

Danos internos detectados pela análise radiográfica, independente da causa, afetam a germinação das sementes das espécies estudadas, com exceção daqueles de menores dimensões, distantes do eixo-embrionário.

\section{REFERÊNCIAS}

BASKIN, C.C.; BASKIN, J.M. Seeds ecology, biogeography and evolution of dormancy and germination. San Diego.: California: Academic Press, $1998.666 \mathrm{p}$.

BATTISTI, A.; CANTINI, R.; FECI, E.; FRIGIMELICA, G.; GUIDO, M.; RAQUES, A. Detection and evaluation of seed damage of cipress, Cupressus sempervirens L. Italy. Seed Science and Technology, v.28, n.3, p.729-738, 2000 .

BILIA, D.A.C.; BARBEDO, C.J.; MALUF, A. M. Germinação de diásporos de canela (Ocotea corymbosa (Meissn.) Mez - LAURACEAE) em função da temperatura, do substrato e da dormência. Revista Brasileira de Sementes, v.20, n.1, p.189-194, 1998.

BINO, R.J.; AARTSE, J.W.; BURG, W.J. van der. Nondestructive X-ray of Arabidopsis embryo mutants. Seed Science Research, v.3, n.2, p.167-170, June 1993.

BONNER, F.T. Storage of seeds: potential and limitations for germoplasm conservation. Forest Ecology and Management, v.35, n.1/2, p.35-43, June 1990.

BRASIL. Ministério da Agricultura e da Reforma Agrária. Normais Climatológicas 1961-1990. Brasília, DF: Departamento Nacional de Meteorologia, 1992a. 84 p.

BRASIL. Ministério da Agricultura e Reforma Agrária. Secretaria Nacional de Defesa Agropecuária. Departamento Nacional de Produção Vegetal. Coordenação de Laboratório Vegetal. Regras para Análise de Sementes. Brasília, DF, 1992b. 365 p.
BURG. W.J. van der; AARTSE, J.W.; ZWORL, R.A. van, JALINK, H.; BINO, RJ. Predicting tomato seedling morphology by X-ray analysis of seeds. Journal American Society for Horticultural Science, v.119, n.2, p.258-263, 2004.

CARVALHO, D.A.; OLIVEIRA-FILHO, A.T.; VILELA, E.de A.; VAN DEN BERG, E.; FONTES, M.A.L. Estudos florísitcos e fitossociológicos em remanescentes de Florestas Ripárias do Alto São Francisco e Bacia do Rio Doce- MG. Lavras: Universidade Federal de Lavras/ CEMIG, 1999. 39 p.

CARVALHO, L.R. Conservação de sementes de espécies dos gêneros Nectandra, Ocotea e Persea (Lauraceae). 2006. 75 f: il. Tese (Doutorado) - Universidade Federal de Lavras, Lavras.

CARVALHO, M.L.M de; VON PINHO, E.V.R. Armazenamento de sementes. 1997. 67 f. Curso de PósGraduação "Lato Sensu" (Especialização) a Distância: Produção e Tecnologia de Sementes. Universidade Federal de Lavras/ FAEPE, Lavras.

CHIN, H.F. Recalcitrant seeds. Malaysia: Universiti Pertanian Malaysia, 1989. 17p. (Extension Bulletin, 288).

DAVIDE, A.C.; CARVALHO, L.R.C.; CARVALHO, M.L.M.; GUIMARÃES, R.M. Classificação fisiológica de sementes de espécies florestais pertencentes à família Lauraceae quanto à capacidade de armazenamento. CERNE, v.9, n.1, p.29-35, 2003.

INTERNATIONAL RULES FOR SEED TESTING. ISTA. Seed science and technology. 1999. 333 p. Supplement.

INTERNATIONAL RULES FOR SEED TESTING. ISTA. Zürich, 2004. 180 p.

KÖPPEN, W. Das geographische system der klimate. In: KÖPPEN, W.; GEIGER, R. (Ed.). Handbuch der Klimatologie. Berlin: 1936. v. 1, p. 1-44, part C.

LORENZI, H. Árvores brasileiras: manual de identificação e cultivo de plantas arbóreas nativas do Brasil. Nova Odessa: Plantarum, 1992. v.1, 382 p.

LORENZI, H. Árvores brasileiras: manual de identificação e cultivo de plantas arbóreas nativas do Brasil. 2. ed. Nova Odessa: Instituto Plantarum de Estudos da Flora, 1998. v.2, $352 \mathrm{p}$

MACHADO, C.F.; CÍCERO, S.M. Aroeira-branca (Litthraea molleoides (Vell.) Engl. -Anacardiaceae) seed quality evaluation by the X-ray test. Scientia Agricola, v.60, n.2, p.393-397, abr./jun. 2003. 
MASETTO, T.E. Estudos da sensibilidade à dessecação em sementes de Eugenia handroana D. Legrand (Myrtaceae). 200560 f. Dissertação (Mestrado em Engenharia Florestal) Universidade Federal de Lavras, Lavras.

MATTOS, P.P.; MEDEIROS, A.C.S. Uso de raios-x na avaliação de sementes de pata-de-vaca (Bauhinia forticata) e erva-mate (Ilex paraguariensis). Colombo: Embrapa Florestas, 2000. 3 p. (Embrapa Florestas. Pesquisa em andamento, 88).

OLIVEIRA, L.M.; CARVALHO, M.L.M.; DAVIDE, A.C. Utilização do teste de raios-X na avaliação da qualidade de sementes de canafístula (Peltophorum dubium (Sprengel) Taubert). Revista Brasileira de Sementes, v.25, n.1, p.116-120, 2003.

OLIVEIRA, L.M.; CARVALHO, M.L.M.; GUIMARÃES, R.M.; MASETTO, T.E. Avaliação da qualidade de sementes de Tabebuia serratifolia Vahl Nich. e T. impetiginosa (Martius ex A. P. de Candolle) Standley - (Bignoniaceae) pelo teste de raios X. Revista Brasileira de Sementes, v.26, n.2, p.138-143, 2004.

OLIVEIRA-FILHO, A.T.; VILELA, E.A.; CARVALHO, D.A.; GAVILANES, M.L. Remanescentes de matas ciliares do Alto e Médio Rio Grande: florística e fitossociologia. Belo Horizonte: CEMIG/UFLA/FAEPE, 1995. $27 \mathrm{p}$

PINTO, L.V.A. Caracterização física da sub-bacia do Ribeirão Santa Cruz Lavras, MG, e propostas de recuperação de áreas no entorno de nascentes. 2003. 165 f. Dissertação (Mestrado em Engenharia Florestal) Universidade Federal de Lavras, Lavras.

ROBERTS, E.H. Predicting the storage life of seeds. Seed Science and Technology, v.1, n.4, p.499-514, 1973.

ROSA, L. dos S.; OHASHI, S.T. Influência do substrato e do grau de maturação dos frutos sobre a germinação do pau-rosa (Aniba rosaeodora Ducke). Revista de Ciências Agrárias, n.31, p.49-55, jan./jun. 1999.
SEBBEN, A.M. Número de árvores matrizes e conceitos genéticos na coleta de sementes para reflorestamentos com espécies nativas. Revista do Instituto Florestal, v.14, n.2. p.115-132, dez. 2002.

SILVA, A. da. Padrão de florescimento e frutificação, caracterização de diásporos e germinação de sementes de canela-preta (Ocotea catharinensis Mez.). 1997. $94 \mathrm{f}$. Dissertação (Mestrado) - Universidade Estadual Paulista. Faculdade de Ciências Agrárias e Veterinária, Jaboticabal.

SIMAK, M. Testing of forest tree and shrub seeds by X-radiography. In: GORDON, A.G.; GOSLING, P.; WANG, B.S.P. (Ed.). Tree and shrub seed handbook. Zurich: ISTA, 1991. p.1-28.

SOUZA, J.A. de. Avaliação das estratégias de recuperação de áreas degradadas pela mineração de bauxita em Poços de Caldas (MG). 1997. 104 f. Tese (Doutorado em Agronomia) - Universidade Federal de Lavras, Lavras.

TERRY, J.; PROBERT, R.J.; LININGTON, S.H. Processing and Maintenance of the Millenium Seed Bank Collections. In: SMITH, R. D.; LININGTON, S. H.; DICKIE, J. B.; LININGTON, S. H.; PRITCHARD, H. W.; PROBERT, R. $\mathrm{J}$. Seed Conservation turning science into practice. Kew: Royal Botanic Gardens, 2003. p.307-325.

TONETTI, O.A.O. Melhoria da qualidade física e estudos da germinação de sementes de candeia (Eremanthus incanus (Less) e Eremanthus erythropappus (DC) Mac Leish). 2004. 81 f. Dissertação (Mestrado em Engenharia Florestal) - Universidade Federal de Lavras, Lavras.

VERNALHA, M.M. "Heilipus parvulus" Bohn, 1943, praga da imbúia (Phoebe porosa) no horto florestal de Vila Velha. In: CONGRESSO FLORESTAL BRASILEIRO, 1., 1953, Curitiba. Anais... Curitiba: Instituto Nacional do Pinho, 1953. p.125-128. 